\title{
Review
}

Matthew B. Amdahl, Anthony W. DeMartino and Mark T. Gladwin*

\section{Inorganic nitrite bioactivation and role in physiological signaling and therapeutics}

https://doi.org/10.1515/hsz-2019-0349

Received August 16, 2019; accepted November 2, 2019; previously published online November 19, 2019

\begin{abstract}
The bioactivation of inorganic nitrite refers to the conversion of otherwise 'inert' nitrite to the diatomic signaling molecule nitric oxide (NO), which plays important roles in human physiology and disease, notably in the regulation of vascular tone and blood flow. While the most well-known sources of NO are the nitric oxide synthase (NOS) enzymes, another source of NO is the nitrate-nitriteNO pathway, whereby nitrite (obtained from reduction of dietary nitrate) is further reduced to form NO. The past few decades have seen extensive study of the mechanisms of NO generation through nitrate and nitrite bioactivation, as well as growing appreciation of the contribution of this pathway to NO signaling in vivo. This review, prepared for the volume 400 celebration issue of Biological Chemistry, summarizes some of the key reactions of the nitrate-nitrite-NO pathway such as reduction, disproportionation, dehydration, and oxidative denitrosylation, as well as current evidence for the contribution of the pathway to human cardiovascular physiology. Finally, ongoing efforts to develop novel medical therapies for multifarious conditions, especially those related to pathologic vasoconstriction and ischemia/reperfusion injury, are also explored.
\end{abstract}

Keywords: ischemia/reperfusion; nitrate; nitric oxide.

*Corresponding author: Mark T. Gladwin, Heart, Lung, Blood, and Vascular Medicine Institute, University of Pittsburgh, Pittsburgh, PA 15261, USA; and Division of Pulmonary, Allergy, and Critical Care Medicine, University of Pittsburgh, Pittsburgh, PA 15213, USA, e-mail: gladwinmt@upmc.edu

Matthew B. Amdahl and Anthony W. DeMartino: Heart, Lung, Blood, and Vascular Medicine Institute, University of Pittsburgh, Pittsburgh, PA 15261, USA. https://orcid.org/0000-0002-5169-3340 (M.B. Amdahl); https://orcid.org/0000-0001-5303-5758 (A.W. DeMartino)

\section{Introduction: the nitrate-nitrite-NO pathway}

For some time, the nitrite anion $\left(\mathrm{NO}_{2}^{-}\right)$was considered biologically inert. However, the conversion of nitrite to NO and other oxides of nitrogen (termed bioactivation of nitrite) and ensuing participation in a wide variety of biological signaling pathways has more recently become widely accepted. Numerous studies have elucidated the chemical reactions governing the bioactivation of nitrite and subsequent NO signaling (Cosby et al., 2003; KimShapiro and Gladwin, 2014; Liu et al., 2015). Generally, these nitrite reactions result in direct generation of nitric oxide (e.g. nitrite reduction), or generation of other nitrogen species that serve as other NO precursors (i.e. nitrite anhydrase reactions that form dinitrogen trioxide, $\mathrm{N}_{2} \mathrm{O}_{3}$, or oxidation to form nitrogen dioxide, $\mathrm{NO}_{2}{ }^{\circ}$ ), all leading to $\mathrm{NO}$ signaling via soluble guanylyl cyclase (sGC) activation, tyrosine nitration, or thiol nitrosation (Wang et al., 2004; Nagababu et al., 2007; Kim-Shapiro and Gladwin, 2014).

The nitrate-nitrite-NO pathway contributes to endothelial nitric oxide synthase (eNOS)-independent NO signaling in physiology and pathophysiology (Basu et al., 2007; Grubina et al., 2007). This pathway plays an important role in processes including the regulation of hypoxic vasodilation, blood pressure homeostasis, adaptation to ischemia and reperfusion, and alteration of platelet function (Radomski et al., 1987; Broekman et al., 1991; Jeffers et al., 2005; Robinson and Lancaster, 2005; Velmurugan et al., 2013; Kapil et al., 2015). The fundamental importance of this pathway in vivo as well as the search for potential therapeutics based on the nitrate-nitrite-NO axis remain active areas of research.

\section{Key reactions of the nitrate- nitrite-NO pathway}

The nitrate-nitrite-NO pathway (Figure 1) constitutes a number of chemical reactions, mostly reductive 


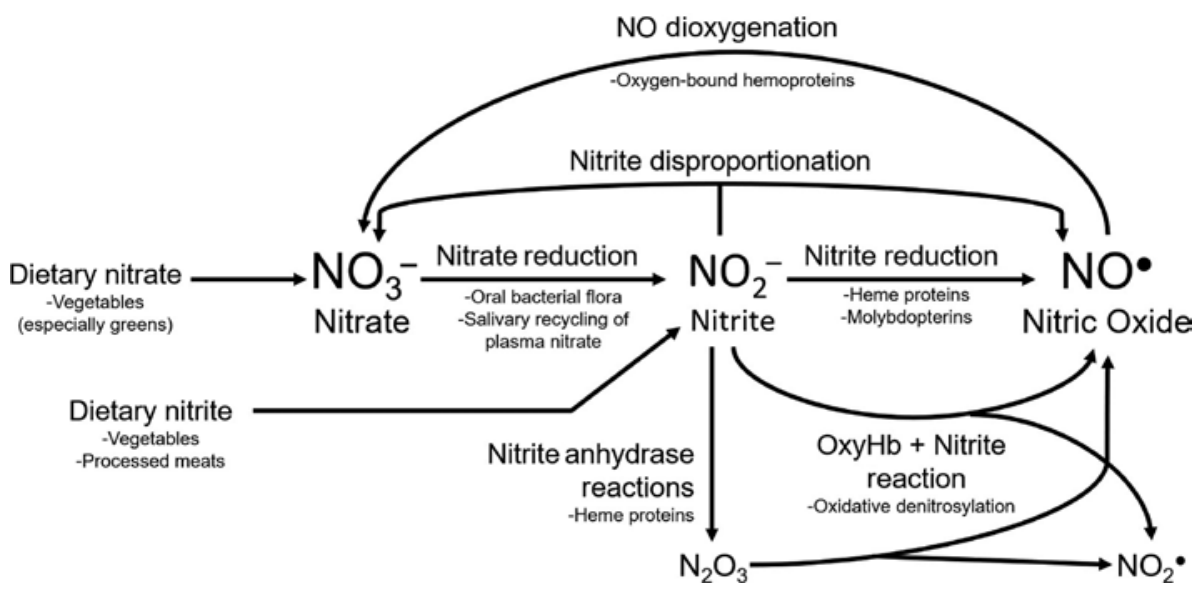

Figure 1: Summary of the nitrate-nitrite-NO pathway, including the conversion of nitrate to nitrite to NO via various mechanisms and the oxidation of NO back to nitrate.

$\mathrm{N}_{2} \mathrm{O}_{3}$, while not explicitly part of the nitrate/nitrite/NO pathway, is depicted because it is an intermediate formed by both nitrite anhydrase and nitrite disproportionation reactions, and serves as a nitrosating agent or means of NO escape from red blood cells [as the disproportionation reaction to $\mathrm{NO}$ and nitrogen dioxide (a radical) is relatively slower than $\mathrm{NO}$ consumption by oxyHb]. Nitrogen dioxide $\left(\mathrm{NO}_{2}{ }_{2}\right)$ is an oxidant that triggers nitration of several biologically relevant species.

proton-electron transfer reactions catalyzed by native mammalian proteins and those of commensal bacteria. These commensal bacteria reduce nitrate to nitrite (Kapil et al., 2013), and a recent study found that such bacteria are strictly required for nitrate bioactivation (Moretti et al., 2019). The rest of the pathway concerns bioactivation of nitrite, typically conversion of nitrite to bioactive NO. Other depicted reactions provide further regulation of nitrate-nitrite-NO signaling and have important effects on physiology. These reactions are discussed in detail below.

\section{Key reactions: nitrite bioactivation via nitrite reduction}

The most studied mechanism of nitrite bioactivation in vivo is nitrite reduction, whereby a protein donates an electron to nitrite in the presence of a proton source to form NO, becoming oxidized in the process as follows (in equation 1):

$$
\begin{gathered}
\mathrm{NO}_{2}{ }^{-}+\mathrm{H}^{+}+\text {Nitrite Reductase }{ }^{\mathrm{n}+} \rightarrow \mathrm{NO}+\mathrm{OH}^{-} \\
+ \text {Nitrite Reductase }{ }^{(\mathrm{n}+1)+}
\end{gathered}
$$

Numerous proteins, specifically metalloproteins, have been documented to reduce nitrite. The two best-known classes of nitrite-reducing metalloproteins are hemebased proteins and molybdopterins.

Heme-based proteins reduce nitrite to NO via an electron transfer reaction at the heme iron. This reaction requires the heme iron to be in the ferrous $\left(\mathrm{Fe}^{2+}\right)$ state without bound ligand (commonly referred to as the 'deoxy' state) (Doyle et al., 1981; Huang et al., 2005a,b). For deoxyhemoglobin, a major source of NO signaling from nitrite, equation 1 is rewritten as

$$
\mathrm{NO}_{2}^{-}+\mathrm{H}^{+}+\mathrm{HbFe}^{2+} \rightarrow \mathrm{NO}+\mathrm{OH}^{-}+\mathrm{HbFe}^{3+}
$$

Heme-containing proteins, known as hemoproteins, include hemoglobin $(\mathrm{Hb})$, myoglobin $(\mathrm{Mb})$, cytoglobin (Cygb), neuroglobin (Ngb), and the non-mammalian globin X (GbX); these are the most well-documented heme-based nitrite reductases (Doyle et al., 1981; Shiva et al., 2007; Tiso et al., 2011; Li et al., 2012a,b; Corti et al., 2016). That said, several other heme proteins have also been indicated to perform nitrite reduction such as cytochrome c, cytochrome c oxidase (Cox), and endothelial - but not inducible or neuronal - nitric oxide synthase (eNOS) (Kim-Shapiro and Gladwin, 2014).

The second class of metalloproteins that have been recently documented to reduce nitrite is molybdopterins. These molybdenum-based proteins include xanthine oxidoreductase (XOR), aldehyde oxidase (AO), sulfite oxidase (SO), and the mitochondrial amidoxime reducing components (mARCs) (Webb et al., 2004; Havemeyer et al., 2006; Li et al., 2008; Hille, 2013; Sparacino-Watkins et al., 2014). Nitrite reduction by molybdenum-containing enzymes and their fundamental mechanisms are a current area of active research in terms of the molybdopterins' biological significance. 


\section{Key reactions: NO escape from erythrocytes via nitrite anhydrase reactions}

Ferrous hemoproteins with oxygen bound ('oxy' form) react near the diffusion limit with $\mathrm{NO}\left(k \sim 10^{8} \mathrm{M}^{-1} \mathrm{~s}^{-1}\right)$ in a reaction known as NO dioxygenation, oxidizing NO to nitrate (Gardner et al., 1998, 2010; Gardner, 2005). While this reaction is responsible for tamping down NO signaling from all sources, it is problematic from a theoretical standpoint in terms of $\mathrm{NO}$ generation from nitrite by hemoglobin, which is localized in red blood cells. Coupled with the affinity of deoxyhemoglobin for NO (Table 1), modeling of NO generation from nitrite in erythrocytes suggests that free NO should have a half-life on the order of only $1 \mu \mathrm{s}$ and would only diffuse roughly $0.1 \mu \mathrm{m}$ before being consumed by the abundant hemoglobin within the red cell (Kim-Shapiro and Gladwin, 2014). Thus, one significant question that emerged in the study of NO generation by nitrite and hemoglobin is how NO is able to escape the red cell and reach the vascular wall to exert vasodilatory effects. Several mechanism have been suggested including localization of NO generation to near the red cell membrane, allowing for some escape, as well as the formation of intermediates such $\mathrm{N}_{2} \mathrm{O}_{3}$ or nitrosothiols on protein surfaces (Jeffers et al., 2005; Robinson and Lancaster, 2005).

S-nitrosothiols have long been explored as mediators of NO export, with the $\beta 93$ cysteine residue in $\mathrm{Hb}$ identified as a site for -SNO formation and subsequent NO export (Gow and Stamler, 1998). Recent work, however, has shown that mutant $\mathrm{Hb}$ that lacks this residue does not alter erythrocyte-derived NO bioactivity, suggesting some alternate unknown mechanism for $\mathrm{NO}$ export from the red cell (Sun et al., 2019).
One proposed mechanism for NO signaling from nitrite in the red blood cell involves generation of dinitrogen trioxide $\left(\mathrm{N}_{2} \mathrm{O}_{3}\right)$ (Basu et al., 2007; Gladwin et al., 2009). While $\mathrm{N}_{2} \mathrm{O}_{3}$ generally is highly reactive and rapidly disproportionates to generate $\mathrm{NO}$, it has a longer relative lifetime than NO and is also diffusible, thus persisting longer in the red cell than NO itself. Hemoglobin would generate $\mathrm{N}_{2} \mathrm{O}_{3}$ via a nitrite anhydrase reaction (aka ferriheme-nitrite disproportionation), for which two mechanisms have been proposed. In the first, nitrite reacts with deoxyhemoglobin to form a ferric $\left(\mathrm{Fe}^{3+}\right)$ nitrosyl intermediate, which subsequently reacts with a second nitrite molecule to form $\mathrm{N}_{2} \mathrm{O}_{3}$ as shown in equations 3 and 4 (Fernandez et al., 2004; Nagababu et al., 2007; Salgado et al., 2009).

$\mathrm{NO}_{2}^{-}+\mathrm{H}^{+}+\mathrm{HbFe}^{2+} \rightarrow\left(\mathrm{HbFe}^{3+}-\mathrm{NO} \leftrightarrow \mathrm{HbFe}^{2+}-\mathrm{NO}^{+}\right)+\mathrm{OH}^{-}$

$\left(\mathrm{HbFe}^{3+}-\mathrm{NO} \leftrightarrow \mathrm{HbFe}^{2+}-\mathrm{NO}^{+}\right)+\mathrm{NO}_{2}^{-} \rightarrow \mathrm{HbFe}^{2+}+\mathbf{N}_{2} \mathbf{O}_{3}$

It has been suggested, however, that the ferric nitrosyl species may release NO too rapidly to allow for any significant reactivity with nitrite. In the alternative mechanism, ferric hemoglobin reacts directly with nitrite, generating an intermediate with some ferrous nitrogen dioxide characteristics; this intermediate is then able to react with NO as shown in equations 5 and 6 (Basu et al., 2007).

$$
\begin{aligned}
& \mathrm{NO}_{2}^{-}+\mathrm{HbFe}^{3+} \rightarrow\left(\mathrm{HbFe}^{3+}-\mathrm{NO}_{2}^{-} \leftrightarrow \mathrm{HbFe}^{2+}-\mathrm{NO}_{2}^{-}\right) \\
& \left(\mathrm{HbFe}^{3+}-\mathrm{NO}_{2}^{-} \leftrightarrow \mathrm{HbFe}^{2+}-\mathrm{NO}_{2}^{-}\right)+\mathrm{NO} \rightarrow \mathrm{HbFe}^{2+}+\mathbf{N}_{2} \mathbf{O}_{3}
\end{aligned}
$$

This mechanism is limited by a relatively low affinity of ferric hemoglobin for nitrite, which limits the rate of the

\begin{tabular}{|c|c|c|c|}
\hline Reaction & Protein & Rate constant $\left(\mathbf{M}^{-1} \mathbf{S}^{-1}\right)$ & Reference \\
\hline Nitrite & $\mathrm{Hb}$ (T state) & 0.12 at $25^{\circ} \mathrm{C}$ & (Huang et al., 2005a,b) \\
\hline \multirow[t]{8}{*}{ reduction } & $\mathrm{Hb}$ (R state) & 6.0 at $25^{\circ} \mathrm{C}$ & (Huang et al., 2005a,b) \\
\hline & $\mathrm{Mb}$ & 6.0 at $25^{\circ} \mathrm{C}$ & (Huang et al., 2005a,b) \\
\hline & & 12.0 at $37^{\circ} \mathrm{C}$ & (Shiva et al., 2007) \\
\hline & Cygb without disulfide & 0.63 at $25^{\circ} \mathrm{C}$ & (Reeder and Ukeri, 2018) \\
\hline & Cygb with disulfide & 32.3 at $25^{\circ} \mathrm{C}$ & (Reeder and Ukeri, 2018) \\
\hline & Ngb without disulfide & 0.062 at $25^{\circ} \mathrm{C}$ & (Tiso et al., 2011) \\
\hline & Ngb with disulfide & 0.12 at $25^{\circ} \mathrm{C}$ & (Tiso et al., 2011) \\
\hline & $\mathrm{GbX}$ & 26.7 at $37^{\circ} \mathrm{C}$ & (Corti et al., 2016) \\
\hline Nitric oxide & $\mathrm{Hb}$ & $9 \times 10^{7}$ at $20^{\circ} \mathrm{C}$ & (Herold et al., 2001) \\
\hline \multirow[t]{2}{*}{ dioxygenation } & $\mathrm{Mb}$ & $4 \times 10^{7}$ at $20^{\circ} \mathrm{C}$ & (Herold et al., 2001) \\
\hline & Cygb & $3 \times 10^{7}$ at $37^{\circ} \mathrm{C}$ & (Liu et al., 2012) \\
\hline Nitric oxide & $\mathrm{Hb}$ (R or T state) & $2.1 \times 10^{7}$ & (Huang et al., 2002) \\
\hline binding & Cygb & $1 \times 10^{8}$ at $37^{\circ} \mathrm{C}$ & (Liu et al., 2012) \\
\hline
\end{tabular}

Table 1: Summary of rate constants for nitrite reduction, NO dioxygenation, and NO binding. 
first reaction, and by the rapid reactions of NO with oxygenated and deoxygenated hemoglobin which would limit the NO available for the second reaction.

It has been suggested that the enzyme carbonic anhydrase may perform nitrite dehydration reactions as well, with previous literature documenting NO production from nitrite by carbonic anhydrase II that was paradoxically increased by carbonic anhydrase inhibitors (Aamand et al., 2009). However, as indicated by the nitrite anhydrase activity of hemoglobin above, a redox active metal center is essential; more recent attempts to replicate these studies, have been unable to find any evidence of nitrite dehydration activity (Andring et al., 2018; Wang et al., 2019).

\section{Key reactions: nitrite bioactivation by oxyhemoglobin}

Nitrite can also react directly with the ferrous oxy-form of hemoglobin to form oxidative intermediates like nitrogen dioxide $\left(\mathrm{NO}_{2}{ }^{-}\right) . \mathrm{NO}_{2}{ }^{\cdot}$ can react with iron-nitrosyl-hemoglobin directly in a reaction known as oxidative denitrosylation, which may release $\mathrm{NO}$ and might facilitate NO export from the red cell (Grubina et al., 2007).

When deoxyhemoglobin alone reacts with nitrite, the NO formed via nitrite reduction is trapped as nitrosylated hemoglobin upon re-reduction of the hemoglobin (see below) or reaction with a second heme. When deoxy and oxyhemoglobin are present together as they are in red cells in vivo, consumption of the iron-nitrosyl with corresponding release of NO is observed. Thus, nitrite also reacts with oxyhemoglobin; while the mechanism is not fully understood, it involves several autocatalytic intermediates including ferryl $\left(\mathrm{Fe}^{4+}\right)$-hemoglobin, hydrogen peroxide, and nitrogen dioxide $\left(\mathrm{NO}_{2}{ }^{\prime}\right)$ (Kosaka et al., 1982; Keszler et al., 2008; Hathazi et al., 2018) (generalized in equation 7).

$$
\mathrm{HbFe}^{2+}-\mathrm{O}_{2}+\mathrm{NO}_{2}^{-} \rightarrow \mathrm{NO}_{2}^{-}+\text {other intermediates }
$$

The generated nitrogen dioxide then could react with the ferrous nitrosylated hemoglobin and oxidize it to the ferric-nitrosyl form. Ferric hemoglobin has notably lower affinity for NO than ferrous, and thus oxidation leads to release of the NO. This process has been termed oxidative denitrosylation - the endpoint of the nitrite 'oxy'-reaction - and is summarized in equation 8.

$$
\mathrm{HbFe}^{2+}-\mathrm{NO}+\mathrm{NO}_{2}{ }^{\cdot} \rightarrow \mathrm{HbFe}^{3+}+\mathrm{NO}+\mathrm{NO}_{2}^{-}
$$

\section{Key reactions: nitrite bioactivation via nitrite disproportionation}

Another set of reactions which directly generate NO from nitrite are those involved in non-enzymatic nitrite disproportionation. These reactions occurs in low $\mathrm{pH}$ environments and result in the generation of NO from nitrite as shown in equations 9-11.

$$
\begin{gathered}
\mathrm{NO}_{2}^{-}+\mathrm{H}^{+} \leftrightharpoons \mathrm{HNO}_{2} \quad\left(\mathrm{pK}_{\mathrm{a}} \sim 3.3\right) \\
2 \mathrm{HNO}_{2} \leftrightharpoons \mathrm{N}_{2} \mathrm{O}_{3}+\mathrm{H}_{2} \mathrm{O} \\
\mathrm{N}_{2} \mathrm{O}_{3} \rightarrow \mathrm{NO}+\mathrm{NO}_{2} \cdot
\end{gathered}
$$

This reaction has been documented to rapidly generate $\mathrm{NO}$ in the acidic environment of the stomach (Lundberg et al., 1994), but is also thought to be a significant source of $\mathrm{NO}$ in ischemic tissue where the local $\mathrm{pH}$ decreases (Zweier et al., 1995; Samouilov et al., 1998). Among all reactions discussed in this review, only this one is enzyme-independent, and thus able to occur wherever enough nitrite is present with a proton source.

\section{Modulation of NO signaling from nitrite by heme proteins}

The ability of globins to perform both nitrite reduction and NO dioxygenation allows these proteins to both increase and decrease NO levels and NO signaling depending on local oxygen tension and $\mathrm{pH}$. As shown in equation 2, nitrite reduction requires the deoxy heme and a proton; this reaction will thereby be favored in hypoxic and acidic conditions. NO dioxygenation, in contrast, requires the oxygen-bound form of heme, and so will be favored in oxygen-rich conditions. For hemoglobin, the rate of nitrite reduction is maximized at $50 \%$ oxygen saturation, as partial oxygen binding exerts an allosteric effect and shifts the protein into the R conformation, which reduces nitrite roughly 100 times faster than the $\mathrm{T}$ state of completely unbound hemoglobin (Huang et al., 2005b; Gladwin and Kim-Shapiro, 2008).

Environmental conditions influence hemoprotein reactivity via other mechanisms as well. For example, recent studies of cytoglobin have shown an additional mechanism of redox sensitivity that stems from two cysteine residues on the surface of the protein. Formation of a disulfide bridge between these cysteines greatly 
increases cytoglobin's rate of nitrite reduction (Beckerson et al., 2015; Reeder and Ukeri, 2018). In fact, this form has the largest reported rate constant for nitrite reduction of any known mammalian protein (Table 1). Specifically, this disulfide formation can be triggered by the binding of various lipids to cytoglobin (Reeder et al., 2011; Tejero et al., 2016). A similar mechanism has been observed for neuroglobin as well, though the effect is far less pronounced (Tiso et al., 2011).

Overall, these mechanisms allow hemoproteins in the presence of nitrite to increase NO levels in hypoxic, acidic or oxidative conditions, but lower NO levels in normoxic conditions. This environment-sensitive modulation of NO signaling is thought to play a significant role in hypoxic vasodilation, which leads to increased blood flow to tissues with low oxygen levels (Gladwin et al., 2000; Cosby et al., 2003) and is an important mechanism by which metabolically active tissues with increased oxygen consumption can receive sufficient oxygen delivery from blood to continue aerobic respiration.

Finally, both nitrite reduction and NO dioxygenation result in the oxidation of the heme iron to the ferric state, limiting the amount of NO that can be produced or consumed to a stoichiometric equivalent. To overcome this limitation, localized reducing systems exist that rapidly and repeatedly reduce the heme iron back to the ferrous form, allowing for high turnover of these reactions and effectively catalytic NO consumption or production. One such reducing system is the combination of cytochrome $b_{5}$ (CYB5) and cytochrome $b_{5}$ reductase (CYB5R), which together accept electrons from NADH and shuttles them to globins, reducing the heme iron. This system reduces hemoglobin within erythrocytes and has recently been shown to support very rapid reduction of cytoglobin, thus enabling catalytic NO dioxygenation (Amdahl et al., 2017, 2019). Ascorbate has also been shown to reduce some hemoproteins; the specific reducing system that predominates in vivo varies based on the particular tissue in which the reaction is occurring (Gardner et al., 2010). Thus, these hemoproteins serve as terminal oxidoreductases to regulate NO bioavailability - oxidizing $\mathrm{NO}$ and/or reducing nitrite, depending on the local conditions.

\section{Biological significance of nitrite}

Nitrite and NO have numerous physiologic effects; the best-studied of these is the role of $\mathrm{NO}$ as a vasodilator. In vascular smooth muscle, NO binds and activates the enzyme sGC, triggering production of cGMP, and a subsequent signaling cascade stimulating vasodilation. While NOS is considered the canonical source of NO, the generation of NO from nitrite exerts a significant and independent effect on vascular physiology (Weitzberg and Lundberg, 1998; Webb et al., 2008a,b). This source of NO may also play an important role in maintaining NO signaling during oxidative stress, which can arise from a variety of disease conditions (e.g. sepsis, hypoxia, acute ischemia and ischemia-reperfusion injury) and is known to impair eNOS function (Forstermann and Sessa, 2012).

More recent data elucidates the importance of the nitrate-nitrite-NO axis in physiology. Several studies have shown that infusion of sodium nitrite causes a measurable decrease in blood pressure and an increase in blood flow in both animal and human models (Classen et al., 1990; Gladwin et al., 2000; Cosby et al., 2003; Dejam et al., 2007). This effect was initially seen with supraphysiologic levels of nitrite, but was subsequently found to occur at physiologic nitrite levels (Cosby et al., 2003; Dejam et al., 2007). The vasodilatory effect is potentiated by both exercise (which increases deoxyhemoglobin levels) and acidic conditions, and associated with the temporal formation of NO-bound hemoglobin, suggesting nitrite reduction by red cell hemoglobin is a major mediator of nitrite-induced vasodilation (Modin et al., 2001; Cosby et al., 2003). This postulation is supported by data on platelet activation by NO, indicating that red cells containing deoxyhemoglobin - necessary for nitrite reduction - are required (Srihirun et al., 2012).

One significant source of endogenous nitrite in vivo is reduction of nitrate to nitrite. Humans do not innately possess nitrate reductase enzymes, but these enzymes are present in bacteria that are found in the normal oral flora of humans (Doel et al., 2005). Dietary nitrate is converted to nitrite by these oral bacteria, and this nitrite is then reduced to NO in the vasculature by various nonenzymatic and enzymatic systems as discussed above. This pathway was first shown to have a measurable effect on blood pressure in a study of healthy volunteers, with an observed decrease in diastolic blood pressure and increase in plasma nitrate and nitrite levels after oral nitrate administration (Larsen et al., 2006). Subsequent studies further documented both acute and sustained lowering of blood pressure with dietary nitrate supplementation (Webb et al., 2008a,b; Kapil et al., 2015), while other studies found that use of an antiseptic mouth rinse that killed nitrate-reducing oral bacteria blunted the effects of oral nitrate (Govoni et al., 2008; Petersson et al., 2009; Kapil et al., 2013). Taken together, these findings suggest 
that nitrite obtained from dietary nitrate is a significant mediator of baseline vascular tone and blood pressure, and that impairment of the nitrate-nitrite-NO pathway may thus increase the risk of hypertension.

Further studies have shown that the nitrate-nitrite-NO axis influences more than just vascular tone. For example, there is emerging evidence that inorganic nitrate exerts notable anti-inflammatory effects, and appears to thereby reduce systemic inflammation, endothelial dysfunction, and the progression of atherosclerotic plaques, suggesting dietary nitrate may be protective against a wide variety of inflammatory conditions (Stokes et al., 2009; Jadert et al., 2012; Asgary et al., 2016; Khambata et al., 2017; Raubenheimer et al., 2017).

Another recent study showed that cytoglobin is able to promote healing after vascular injury in mouse models, and that this effect appears mediated primarily through ability of cytoglobin to lower NO levels in the recovering vascular wall via NO dioxygenation (Jourd'heuil et al., 2017). This response suggests that modulation of NO signaling by hemoproteins may play a role in a wide variety of physiological processes that require controlled NO levels, including repair of damaged tissues.

Finally, as mentioned, NO is a potent inhibitor of platelet aggregation, and nitrite inhibits platelet activation and aggregation via nitrite reduction in red blood cells. Studies have shown that dietary nitrate intake in the form of beetroot juice can inhibit ex vivo platelet aggregation in human volunteers (Velmurugan et al., 2013). Interestingly, a recent study found that nitrite provides antiplatelet effects in patients with heart failure with preserved ejection fraction (HFpEF) and atrial fibrillation who are resistant to sodium nitroprusside, a commonly used NO donor (Borgognone et al., 2018). These results suggest that nitrite meaningfully increases NO signaling when other NO donors cannot, although the exact reason for this difference is not currently known.

\section{Therapeutic applications of nitrite}

The final area to be discussed is the emerging field of therapeutics based on the nitrate-nitrite-NO pathway. Nitrite represents a compelling therapeutic molecule due to the relatively short half-life of NO in vivo, which has been estimated to be on the order of milliseconds in plasma (Rassaf et al., 2002). While exogenous NO given directly would be rapidly consumed and thus must be administered continuously, nitrite remains in the plasma longer with a half-life on the order tens of minutes, providing a more prolonged increase in NO signaling with intermittent dosing (Kelm, 1999; Oldfield et al., 2013; Rix et al., 2015). Intermittent dosing is even more viable with nitrate, which has a halflife on the order of several hours (Lundberg et al., 2008; Bondonno et al., 2015). Nitrite therapy works on a wide range of physiologic targets, some of which are summarized in Figure 2.

Given the vasodilatory effects of NO, nitrite is being explored as a therapy for both systemic and pulmonary hypertension. Studies in human patients have shown that exogenous nitrate and nitrite are both able to reduce blood pressure in hypertensive individuals, credibly via NO signaling (Larsen et al., 2006; Webb et al., 2008a,b; Kapil et al., 2015; Rosenbaek et al., 2018). As discussed, early studies showed an acute decrease in blood pressure with nitrate treatment (Webb et al., 2008a,b), but subsequent studies established a sustained decrease in blood pressure as well, further supporting the therapeutic potential of this pathway (Kapil et al., 2015). For pulmonary hypertension, inhaled NO was initially identified as a potential therapy, but the short half-life of NO requires essentially constant inhalation for a sustained treatment effect. Successive studies found that nitrate and nitrite are both capable of reducing pulmonary artery pressures, suggesting that the nitratenitrite-NO pathway is a promising treatment for hypertension and pulmonary hypertension (Sparacino-Watkins

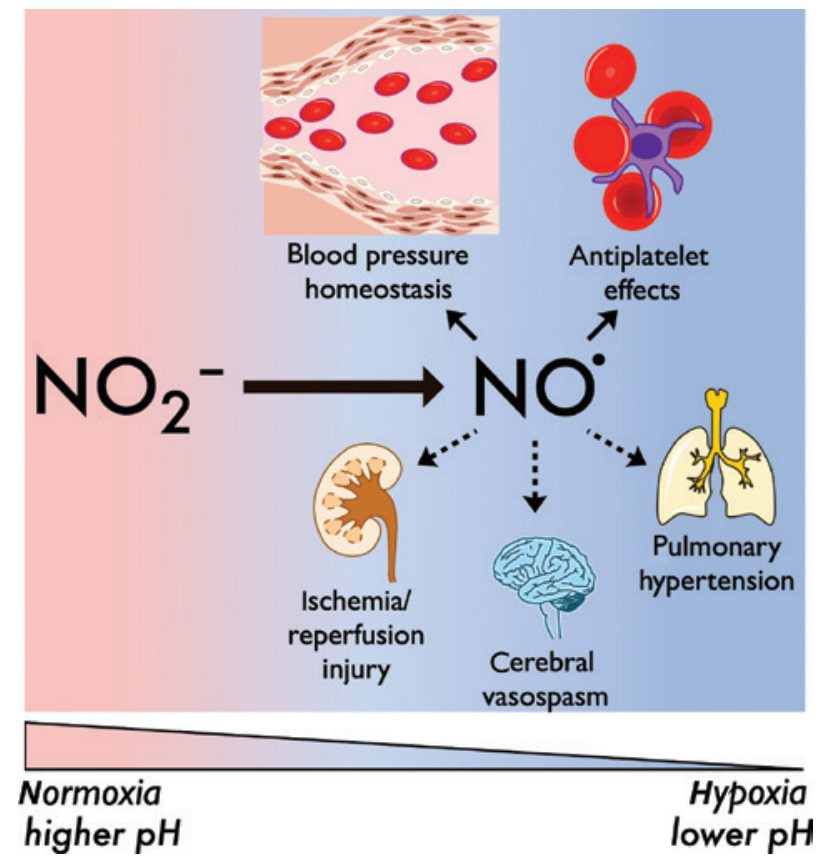

Figure 2: Summary of prominent targets for nitrite-based therapeutics and resultant NO signaling.

General pathways are denoted with solid arrows, while organspecific targets are shown with dashed arrows. 
et al., 2012; Simon et al., 2016). Nitrite has also been shown to prevent subarachnoid hemorrhage-induced cerebral vasospasm in animal models, likely through vasodilatory effects (Pluta et al., 2005; Fathi et al., 2011).

Interestingly, multiple large ( $>1000$ patients) crosssectional studies in Iranian adults found that those with high levels of dietary nitrite or nitrate consumption showed a trend towards decreased incidence of hypertension. Those with high dietary nitrite intake also trended towards decreased incidence of chronic kidney disease (Bahadoran et al., 2016; Golzarand et al., 2016), providing further evidence for the possible benefits of nitrite and nitrate intake. One prospective study also showed that oral nitrate was able to reduce the renal resistive index (RRI) in patients with chronic kidney disease (CKD); as increased RRI is associated with increased cardiovascular mortality in CKD, this suggests nitrate administration may improve prognosis in patients with established CKD (Kemmner et al., 2017).

The mitigation of ischemia-reperfusion injury is another area that is being explored for therapeutic potential of nitrite. Studies in humans with inducible myocardial ischemia have shown that pre-treating with low dose sodium nitrite results in better function and better recovery of the ischemic myocardium (Ingram et al., 2013). Numerous studies in animal models have shown a similar effect in kidneys, with improved reoxygenation and decreased injury after ischemia in animals pretreated with nitrite or nitrate (Tripatara et al., 2007; Cantow et al., 2017; Yang et al., 2017).

A related use for nitrite therapy is in the field of solid organ transplantation, where nitrite has been shown to improve graft function via NO-dependent mechanisms (Li et al., 2012a,b). As transplanted organs are subjected to ischemia once removed from the donor, nitrite likely preserves graft function through the same mechanisms by which it reduces ischemia-reperfusion injury (Bjornsson et al., 2015). While some clinical trials have shown benefits of inhaled nitric oxide in organ transplantation, specifically liver transplants (Lang et al., 2014), there remain no large clinical trials exploring the effect of nitrite administration on transplant outcomes.

More broadly, nitrite is also being explored for its possible cytoprotective effects in a wide variety of pathologic conditions, many of which are related to hypoxia and/or accumulation of reactive oxygen species (ROS) or free radicals. One example is ventilator-induced lung injury, with animal studies showing protective effects of nitrite administration (Pickerodt et al., 2012). There is also evidence that nitrate and nitrite can inhibit prominent ROS-generating systems, including the enzymes NADPH oxidase
(NOX) and xanthine oxidoreductase (XOR) (Lundberg et al., 2018; Carlstrom and Montenegro, 2019). Because ROS and free radicals have been implicated in numerous disease processes, nitrate and nitrite's ability to modulate both the generation and downstream effects of ROS is particularly compelling.

Overall, the therapeutic utility of the nitrate-nitriteNO pathway continues to be explored in a wide variety of clinical contexts. Pre-clinical studies have shown that this pathway exerts promising effects in disease states arising from numerous different underlying causes including vasoconstriction, ischemia, and oxidative stress. Randomized controlled clinical trials using nitrite are now underway, and completion of these trials will provide a better idea of how the nitrate-nitrite-NO pathway might be harnessed to improve patient outcomes.

Acknowledgments: Dr. Gladwin receives research support from NIH grants Funder Id: http://dx.doi. org/10.13039/100000002, 2R01HL098032, Funder Id: http://dx.doi.org/10.13039/100000002， 1R01HL125886, and Funder Id: http://dx.doi.org/10.13039/100000002, 5P01HL103455, T32 HL110849, the Institute for Transfusion Medicine and the Hemophilia Center of Western Pennsylvania.

Conflict of interest statement: Dr. Gladwin is a co-inventor of pending patent applications and planned patents directed to the use of recombinant neuroglobin and hemebased molecules as antidotes for CO poisoning, which have recently been licensed by Globin Solutions, Inc. Dr. Gladwin is a shareholder, advisor and director in Globin Solutions, Inc. Additionally, and unrelated to CO poisoning, Dr. Gladwin is a co-inventor on patents directed to the use of nitrite salts in cardiovascular diseases, which have been licensed by United Therapeutics and Hope Pharmaceuticals, and is a co-investigator in a research collaboration with Bayer Pharmaceuticals to evaluate riociguate as a treatment for patients with SCD.

\section{References}

Aamand, R., Dalsgaard, T., Jensen, F.B., Simonsen, U., Roepstorff, A., and Fago, A. (2009). Generation of nitric oxide from nitrite by carbonic anhydrase: a possible link between metabolic activity and vasodilation. Am. J. Physiol. Heart Circ. Physiol. 297, H2068-H2074.

Amdahl, M.B., Sparacino-Watkins, C.E., Corti, P., Gladwin, M.T., and Tejero, J. (2017). Efficient reduction of vertebrate cytoglobins by the cytochrome $b_{5} /$ cytochrome $b_{5}$ reductase/NADH system. Biochemistry 56, 3993-4004. 
Amdahl, M.B., Petersen, E.E., Bocian, K., Kaliszuk, S.J., DeMartino, A.W., Tiwari, S., Sparacino-Watkins, C.E., Corti, P., Rose, J.J., Gladwin, M.T., et al. (2019). The zebrafish cytochrome $b_{5} /$ cytochrome $b_{5}$ reductase/NADH system efficiently reduces cytoglobins 1 and 2: conserved activity of cytochrome $b_{5}$ /cytochrome $b_{5}$ reductases during vertebrate evolution. Biochemistry 58, 3212-3223.

Andring, J.T., Lomelino, C.L., Tu, C., Silverman, D.N., McKenna, R., and Swenson, E.R. (2018). Carbonic anhydrase II does not exhibit Nitrite reductase or Nitrous Anhydrase Activity. Free Radic. Biol. Med. 117, 1-5.

Asgary, S., Afshani, M.R., Sahebkar, A., Keshvari, M., Taheri, M., Jahanian, E., Rafieian-Kopaei, M., Malekian, F., and Sarrafzadegan, N. (2016). Improvement of hypertension, endothelial function and systemic inflammation following short-term supplementation with red beet (Beta vulgaris L.) juice: a randomized crossover pilot study. J. Hum. Hypertens. 30, 627-632.

Bahadoran, Z., Mirmiran, P., Ghasemi, A., Carlstrom, M., Azizi, F., and Hadaegh, F. (2016). Association between dietary intakes of nitrate and nitrite and the risk of hypertension and chronic kidney disease: Tehran lipid and glucose study. Nutrients. 8, 811.

Basu, S., Grubina, R., Huang, J., Conradie, J., Huang, Z., Jeffers, A., Jiang, A., He, X., Azarov, I., Seibert, R., et al. (2007). Catalytic generation of $\mathrm{N}_{2} \mathrm{O}_{3}$ by the concerted nitrite reductase and anhydrase activity of hemoglobin. Nat. Chem. Biol. 3, 785-794.

Beckerson, P., Wilson, M.T., Svistunenko, D.A., and Reeder, B.J. (2015). Cytoglobin ligand binding regulated by changing haemco-ordination in response to intramolecular disulfide bond formation and lipid interaction. Biochem. J. 465, 127-137.

Bjornsson, B., Bojmar, L., Olsson, H., Sundqvist, T., and Sandstrom, P. (2015). Nitrite, a novel method to decrease ischemia/ reperfusion injury in the rat liver. World J. Gastroenterol. 21, 1775-1783.

Bondonno, C.P., Liu, A.H., Croft, K.D., Ward, N.C., Puddey, I.B., Woodman, R.J., and Hodgson, J.M. (2015). Short-term effects of a high nitrate diet on nitrate metabolism in healthy individuals. Nutrients 7, 1906-1915.

Borgognone, A., Shantsila, E., Worrall, S.M., Prompunt, E., Loka, T., Loudon, B.L., Chimen, M., Ed Rainger, G., Lord, J.M., Turner, A., et al. (2018). Nitrite circumvents platelet resistance to nitric oxide in patients with heart failure preserved ejection fraction and chronic atrial fibrillation. Cardiovasc. Res. 114, 1313-1323.

Broekman, M.J., Eiroa, A.M., and Marcus, A.J. (1991). Inhibition of human platelet reactivity by endothelium-derived relaxing factor from human umbilical vein endothelial cells in suspension: blockade of aggregation and secretion by an aspirininsensitive mechanism. Blood 78, 1033-1040.

Cantow, K., Flemming, B., Ladwig-Wiegard, M., Persson, P.B., and Seeliger, E. (2017). Low dose nitrite improves reoxygenation following renal ischemia in rats. Sci Rep. 7, 14597.

Carlstrom, M. and Montenegro, M.F. (2019). Therapeutic value of stimulating the nitrate-nitrite-nitric oxide pathway to attenuate oxidative stress and restore nitric oxide bioavailability in cardiorenal disease. J. Intern. Med. 285, 2-18.

Classen, H.G., Stein-Hammer, C., and Thoni, H. (1990). Hypothesis: the effect of oral nitrite on blood pressure in the spontaneously hypertensive rat. Does dietary nitrate mitigate hypertension after conversion to nitrite? J. Am. Coll. Nutr. 9, 500-502.

Corti, P., Xue, J., Tejero, J., Wajih, N., Sun, M., Stolz, D.B., Tsang, M., Kim-Shapiro, D.B., and Gladwin, M.T. (2016). Globin X is a six-coordinate globin that reduces nitrite to nitric oxide in fish red blood cells. Proc. Natl. Acad. Sci. U.S.A. 113, 8538-8543.

Cosby, K., Partovi, K.S., Crawford, J.H., Patel, R.P., Reiter, C.D., Martyr, S., Yang, B.K., Waclawiw, M.A., Zalos, G., Xu, X., et al. (2003). Nitrite reduction to nitric oxide by deoxyhemoglobin vasodilates the human circulation. Nat. Med. 9, 1498-1505.

Dejam, A., Hunter, C.J., Tremonti, C., Pluta, R.M., Hon, Y.Y., Grimes, G., Partovi, K., Pelletier, M.M., Oldfield, E.H., Cannon, R.O., et al. (2007). Nitrite infusion in humans and nonhuman primates: endocrine effects, pharmacokinetics, and tolerance formation. Circulation 116, 1821-1831.

Doel, J.J., Benjamin, N., Hector, M.P., Rogers, M., and Allaker, R.P. (2005). Evaluation of bacterial nitrate reduction in the human oral cavity. Eur. J. Oral. Sci. 113, 14-19.

Doyle, M.P., Pickering, R.A., DeWeert, T.M., Hoekstra, J.W., and Pater, D. (1981). Kinetics and mechanism of the oxidation of human deoxyhemoglobin by nitrites. J. Biol. Chem. 256, 12393-12398.

Fathi, A.R., Pluta, R.M., Bakhtian, K.D., Qi, M., and Lonser, R.R. (2011). Reversal of cerebral vasospasm via intravenous sodium nitrite after subarachnoid hemorrhage in primates. J. Neurosurg. 115, 1213-1220.

Fernandez, B.O., Lorkovic, I.M., and Ford, P.C. (2004). Mechanisms of ferriheme reduction by nitric oxide: nitrite and general base catalysis. Inorg. Chem. 43, 5393-5402.

Forstermann, U. and Sessa, W.C. (2012). Nitric oxide synthases: regulation and function. Eur. Heart J. 33, 829-837, $837 a-837 d$.

Gardner, P.R. (2005). Nitric oxide dioxygenase function and mechanism of flavohemoglobin, hemoglobin, myoglobin and their associated reductases. J. Inorg. Biochem. 99, 247-266.

Gardner, P.R., Gardner, A.M., Martin, L.A., and Salzman, A.L. (1998). Nitric oxide dioxygenase: an enzymic function for flavohemoglobin. Proc. Natl. Acad. Sci. U.S.A. 95, 10378-10383.

Gardner, A.M., Cook, M.R., and Gardner, P.R. (2010). Nitric-oxide dioxygenase function of human cytoglobin with cellular reductants and in rat hepatocytes. J. Biol. Chem. 285, 23850-23857.

Gladwin, M.T. and Kim-Shapiro, D.B. (2008). The functional nitrite reductase activity of the heme-globins. Blood 112, 2636-2647.

Gladwin, M.T., Shelhamer, J.H., Schechter, A.N., Pease-Fye, M.E., Waclawiw, M.A., Panza, J.A., Ognibene, F.P., and Cannon 3rd, R.O. (2000). Role of circulating nitrite and S-nitrosohemoglobin in the regulation of regional blood flow in humans. Proc. Natl. Acad. Sci. U.S.A. 97, 11482-11487.

Gladwin, M.T., Grubina, R., and Doyle, M.P. (2009). The new chemical biology of nitrite reactions with hemoglobin: R-state catalysis, oxidative denitrosylation, and nitrite reductase/anhydrase. Acc. Chem. Res. 42, 157-167.

Golzarand, M., Bahadoran, Z., Mirmiran, P., Zadeh-Vakili, A., and Azizi, F. (2016). Consumption of nitrate-containing vegetables is inversely associated with hypertension in adults: a prospective investigation from the Tehran Lipid and Glucose Study. J. Nephrol. 29, 377-384.

Govoni, M., Jansson, E.A., Weitzberg, E., and Lundberg, J.O. (2008). The increase in plasma nitrite after a dietary nitrate load is markedly attenuated by an antibacterial mouthwash. Nitric Oxide 19, 333-337.

Gow, A.J. and Stamler, J.S. (1998). Reactions between nitric oxide and haemoglobin under physiological conditions. Nature 391, 169-173. 
Grubina, R., Huang, Z., Shiva, S., Joshi, M.S., Azarov, I., Basu, S., Ringwood, L.A., Jiang, A., Hogg, N., Kim-Shapiro, D.B., et al. (2007). Concerted nitric oxide formation and release from the simultaneous reactions of nitrite with deoxy- and oxyhemoglobin. J. Biol. Chem. 282, 12916-12927.

Hathazi, D., Scurtu, F., Bischin, C., Mot, A., Attia, A.A.A., Kongsted, J., and Silaghi-Dumitrescu, R. (2018). The reaction of oxy hemoglobin with nitrite: mechanism, antioxidant-modulated effect, and implications for blood substitute evaluation. Molecules 23, 350.

Havemeyer, A., Bittner, F., Wollers, S., Mendel, R., Kunze, T., and Clement, B. (2006). Identification of the missing component in the mitochondrial benzamidoxime prodrug-converting system as a novel molybdenum enzyme. J. Biol. Chem. 281, 34796-34802.

Herold, S., Exner, M., and Nauser, T. (2001). Kinetic and mechanistic studies of the $\mathrm{NO}^{*}$-mediated oxidation of oxymyoglobin and oxyhemoglobin. Biochemistry 40, 3385-3395.

Hille, R. (2013). The molybdenum oxotransferases and related enzymes. Dalton Trans. 42, 3029-3042.

Huang, Z., Ucer, K.B., Murphy, T., Williams, R.T., King, S.B., and Kim-Shapiro, D.B. (2002). Kinetics of nitric oxide binding to R-state hemoglobin. Biochem. Biophys. Res. Commun. 292, 812-818.

Huang, K.T., Keszler, A., Patel, N., Patel, R.P., Gladwin, M.T., Kim-Shapiro, D.B., and Hogg, N. (2005a). The reaction between nitrite and deoxyhemoglobin. Reassessment of reaction kinetics and stoichiometry. J. Biol. Chem. 280, 31126-31131.

Huang, Z., Shiva, S., Kim-Shapiro, D.B., Patel, R.P., Ringwood, L.A., Irby, C.E., Huang, K.T., Ho, C., Hogg, N., Schechter, A.N., et al. (2005b). Enzymatic function of hemoglobin as a nitrite reductase that produces NO under allosteric control. J. Clin. Invest. 115, 2099-2107.

Ingram, T.E., Fraser, A.G., Bleasdale, R.A., Ellins, E.A., Margulescu, A.D., Halcox, J.P., and James, P.E. (2013). Low-dose sodium nitrite attenuates myocardial ischemia and vascular ischemiareperfusion injury in human models. J. Am. Coll. Cardiol. 61, 2534-2541.

Jadert, C., Petersson, J., Massena, S., Ahl, D., Grapensparr, L., Holm, L., Lundberg, J.O., and Phillipson, M. (2012). Decreased leukocyte recruitment by inorganic nitrate and nitrite in microvascular inflammation and NSAID-induced intestinal injury. Free Radic. Biol. Med. 52, 683-692.

Jeffers, A., Xu, X., Huang, K.T., Cho, M., Hogg, N., Patel, R.P., and Kim-Shapiro, D.B. (2005). Hemoglobin mediated nitrite activation of soluble guanylyl cyclase. Comp. Biochem. Physiol. A Mol. Integr. Physiol. 142, 130-135.

Jourd'heuil, F.L., Xu, H., Reilly, T., McKellar, K., El Alaoui, C., Steppich, J., Liu, Y.F., Zhao, W., Ginnan, R., Conti, D., et al. (2017). The hemoglobin homolog cytoglobin in smooth muscle inhibits apoptosis and regulates vascular remodeling. Arterioscler. Thromb. Vasc. Biol. 37, 1944-1955.

Kapil, V., Haydar, S.M., Pearl, V., Lundberg, J.O., Weitzberg, E., and Ahluwalia, A. (2013). Physiological role for nitrate-reducing oral bacteria in blood pressure control. Free Radic. Biol. Med. 55, 93-100.

Kapil, V., Khambata, R.S., Robertson, A., Caulfield, M.J., and Ahluwalia, A. (2015). Dietary nitrate provides sustained blood pressure lowering in hypertensive patients: a randomized, phase 2, double-blind, placebo-controlled study. Hypertension 65, 320-327.

Kelm, M. (1999). Nitric oxide metabolism and breakdown. Biochim. Biophys. Acta 1411, 273-289.

Kemmner, S., Lorenz, G., Wobst, J., Kessler, T., Wen, M., Gunthner, R., Stock, K., Heemann, U., Burkhardt, K., Baumann, M., et al. (2017). Dietary nitrate load lowers blood pressure and renal resistive index in patients with chronic kidney disease: a pilot study. Nitric Oxide 64, 7-15.

Keszler, A., Piknova, B., Schechter, A.N., and Hogg, N. (2008). The reaction between nitrite and oxyhemoglobin: a mechanistic study. J. Biol. Chem. 283, 9615-9622.

Khambata, R.S., Ghosh, S.M., Rathod, K.S., Thevathasan, T., Filomena, F., Xiao, Q., and Ahluwalia, A. (2017). Antiinflammatory actions of inorganic nitrate stabilize the atherosclerotic plaque. Proc. Natl. Acad. Sci. U.S.A. 114, E550-E559.

Kim-Shapiro, D.B. and Gladwin, M.T. (2014). Mechanisms of nitrite bioactivation. Nitric Oxide 38, 58-68.

Kosaka, H., Imaizumi, K., and Tyuma, I. (1982). Mechanism of autocatalytic oxidation of oxyhemoglobin by nitrite. An intermediate detected by electron spin resonance. Biochim. Biophys. Acta 702, 237-241.

Lang Jr, J.D., Smith, A.B., Brandon, A., Bradley, K.M., Liu, Y., Li, W., Crowe, D.R., Jhala, N.C., Cross, R.C., Frenette, L., et al. (2014). A randomized clinical trial testing the anti-inflammatory effects of preemptive inhaled nitric oxide in human liver transplantation. PLoS One 9, e86053.

Larsen, F.J., Ekblom, B., Sahlin, K., Lundberg, J.O., and Weitzberg, E. (2006). Effects of dietary nitrate on blood pressure in healthy volunteers. N. Engl. J. Med. 355, 2792-2793.

Li, H., Cui, H., Kundu, T.K., Alzawahra, W., and Zweier, J.L. (2008). Nitric oxide production from nitrite occurs primarily in tissues not in the blood: critical role of xanthine oxidase and aldehyde oxidase. J. Biol. Chem. 283, 17855-17863.

Li, H., Hemann, C., Abdelghany, T.M., El-Mahdy, M.A., and Zweier, J.L. (2012a). Characterization of the mechanism and magnitude of cytoglobin-mediated nitrite reduction and nitric oxide generation under anaerobic conditions. J. Biol. Chem. 287, 36623-36633.

Li, W., Meng, Z., Liu, Y., Patel, R.P., and Lang, J.D. (2012b). The hepatoprotective effect of sodium nitrite on cold ischemiareperfusion injury. J Transplant. 2012, 635179.

Liu, X., Follmer, D., Zweier, J.R., Huang, X., Hemann, C., Liu, K., Druhan, L.J., and Zweier, J.L. (2012). Characterization of the function of cytoglobin as an oxygen-dependent regulator of nitric oxide concentration. Biochemistry 51 , 5072-5082.

Liu, C., Wajih, N., Liu, X., Basu, S., Janes, J., Marvel, M., Keggi, C., Helms, C.C., Lee, A.N., Belanger, A.M., et al. (2015). Mechanisms of human erythrocytic bioactivation of nitrite. J. Biol. Chem. 290, 1281-1294.

Lundberg, J.O., Weitzberg, E., Lundberg, J.M., and Alving, K. (1994). Intragastric nitric oxide production in humans: measurements in expelled air. Gut. 35, 1543-1546.

Lundberg, J.O., Weitzberg, E., and Gladwin, M.T. (2008). The nitratenitrite-nitric oxide pathway in physiology and therapeutics. Nat. Rev. Drug Discov. 7, 156-167.

Lundberg, J.O., Carlstrom, M., and Weitzberg, E. (2018). Metabolic effects of dietary nitrate in health and disease. Cell Metab. 28, 9-22. 
Modin, A., Bjorne, H., Herulf, M., Alving, K., Weitzberg, E., and Lundberg, J.O. (2001). Nitrite-derived nitric oxide: a possible mediator of 'acidic-metabolic' vasodilation. Acta Physiol. Scand. 171, 9-16.

Moretti, C., Zhuge, Z., Zhang, G., Haworth, S.M., Paulo, L.L., Guimaraes, D.D., Cruz, J.C., Montenegro, M.F., Cordero-Herrera, I., Braga, V.A., et al. (2019). The obligatory role of host microbiota in bioactivation of dietary nitrate. Free Radic. Biol. Med. 145, 342-348.

Nagababu, E., Ramasamy, S., and Rifkind, J.M. (2007). Intermediates detected by visible spectroscopy during the reaction of nitrite with deoxyhemoglobin: the effect of nitrite concentration and diphosphoglycerate. Biochemistry 46, 11650-11659.

Oldfield, E.H., Loomba, J.J., Monteith, S.J., Crowley, R.W., Medel, R., Gress, D.R., Kassell, N.F., Dumont, A.S., and Sherman, C. (2013). Safety and pharmacokinetics of sodium nitrite in patients with subarachnoid hemorrhage: a phase lla study. J. Neurosurg. 119, 634-641.

Petersson, J., Carlstrom, M., Schreiber, O., Phillipson, M., Christoffersson, G., Jagare, A., Roos, S., Jansson, E.A., Persson, A.E., Lundberg, J.O., et al. (2009). Gastroprotective and blood pressure lowering effects of dietary nitrate are abolished by an antiseptic mouthwash. Free Radic. Biol. Med. 46, 1068-1075.

Pickerodt, P.A., Emery, M.J., Zarndt, R., Martin, W., Francis, R.C., Boemke, W., and Swenson, E.R. (2012). Sodium nitrite mitigates ventilator-induced lung injury in rats. Anesthesiology 117, 592-601.

Pluta, R.M., Dejam, A., Grimes, G., Gladwin, M.T., and Oldfield, E.H. (2005). Nitrite infusions to prevent delayed cerebral vasospasm in a primate model of subarachnoid hemorrhage. J. Am. Med. Assoc. 293, 1477-1484.

Radomski, M.W., Palmer, R.M., and Moncada, S. (1987). Endogenous nitric oxide inhibits human platelet adhesion to vascular endothelium. Lancet. 2, 1057-1058.

Rassaf, T., Preik, M., Kleinbongard, P., Lauer, T., Heiss, C., Strauer, B.E., Feelisch, M., and Kelm, M. (2002). Evidence for in vivo transport of bioactive nitric oxide in human plasma. J. Clin. Invest. 109, 1241-1248.

Raubenheimer, K., Hickey, D., Leveritt, M., Fassett, R., Ortiz de Zevallos Munoz, J., Allen, J.D., Briskey, D., Parker, T.J., Kerr, G., Peake, J.M., et al. (2017). Acute effects of nitrate-rich beetroot juice on blood pressure, hemostasis and vascular inflammation markers in healthy older adults: a randomized, placebocontrolled crossover study. Nutrients 9, 1270.

Reeder, B.J. and Ukeri, J. (2018). Strong modulation of nitrite reductase activity of cytoglobin by disulfide bond oxidation: Implications for nitric oxide homeostasis. Nitric Oxide 72, 16-23.

Reeder, B.J., Svistunenko, D.A., and Wilson, M.T. (2011). Lipid binding to cytoglobin leads to a change in haem co-ordination: a role for cytoglobin in lipid signalling of oxidative stress. Biochem. J. 434, 483-492.

Rix, P.J., Vick, A., Attkins, N.J., Barker, G.E., Bott, A.W., Alcorn Jr, H., Gladwin, M.T., Shiva, S., Bradley, S., Hussaini, A., et al. (2015). Pharmacokinetics, pharmacodynamics, safety, and tolerability of nebulized sodium nitrite (AIR001) following repeatdose inhalation in healthy subjects. Clin. Pharmacokinet. 54, 261-272.

Robinson, J.M. and Lancaster Jr, J.R. (2005). Hemoglobin-mediated, hypoxia-induced vasodilation via nitric oxide: mechanism(s) and physiologic versus pathophysiologic relevance. Am. J. Respir. Cell Mol. Biol. 32, 257-261.

Rosenbaek, J.B., Hornstrup, B.G., Jorgensen, A.N., Mortensen, J., Pedersen, E.B., and Bech, J.N. (2018). Effects of sodium nitrite on renal function and blood pressure in hypertensive vs. healthy study participants: a randomized, placebo-controlled, crossover study. J. Hypertens. 36, 666-679.

Salgado, M.T., Nagababu, E., and Rifkind, J.M. (2009). Quantification of intermediates formed during the reduction of nitrite by deoxyhemoglobin. J. Biol. Chem. 284, 12710-12718.

Samouilov, A., Kuppusamy, P., and Zweier, J.L. (1998). Evaluation of the magnitude and rate of nitric oxide production from nitrite in biological systems. Arch. Biochem. Biophys. 357, 1-7.

Shiva, S., Huang, Z., Grubina, R., Sun, J., Ringwood, L.A., MacArthur, P.H., Xu, X., Murphy, E., Darley-Usmar, V.M., and Gladwin, M.T. (2007). Deoxymyoglobin is a nitrite reductase that generates nitric oxide and regulates mitochondrial respiration. Circ. Res. 100, 654-661.

Simon, M.A., Vanderpool, R.R., Nouraie, M., Bachman, T.N., White, P.M., Sugahara, M., Gorcsan 3rd, J., Parsley, E.L., and Gladwin, M.T. (2016). Acute hemodynamic effects of inhaled sodium nitrite in pulmonary hypertension associated with heart failure with preserved ejection fraction. JCI Insight. 1, e89620.

Sparacino-Watkins, C.E., Lai, Y.C., and Gladwin, M.T. (2012). Nitratenitrite-nitric oxide pathway in pulmonary arterial hypertension therapeutics. Circulation 125, 2824-2826.

Sparacino-Watkins, C.E., Tejero, J., Sun, B., Gauthier, M.C., Thomas, J., Ragireddy, V., Merchant, B.A., Wang, J., Azarov, I., Basu, P., et al. (2014). Nitrite reductase and nitric-oxide synthase activity of the mitochondrial molybdopterin enzymes mARC1 and mARC2. J. Biol. Chem. 289, 10345-10358.

Srihirun, S., Sriwantana, T., Unchern, S., Kittikool, D., Noulsri, E., Pattanapanyasat, K., Fucharoen, S., Piknova, B., Schechter, A.N., and Sibmooh, N. (2012). Platelet inhibition by nitrite is dependent on erythrocytes and deoxygenation. PLoS One 7, e30380.

Stokes, K.Y., Dugas, T.R., Tang, Y., Garg, H., Guidry, E., and Bryan, N.S. (2009). Dietary nitrite prevents hypercholesterolemic microvascular inflammation and reverses endothelial dysfunction. Am. J. Physiol. Heart Circ. Physiol. 296, H1281-H1288.

Sun, C.W., Yang, J., Kleschyov, A.L., Zhuge, Z., Carlstrom, M., Pernow, J., Wajih, N., Isbell, T.S., Oh, J.Y., Cabrales, P., et al. (2019). Hemoglobin $\beta 93$ cysteine is not required for export of nitric oxide bioactivity from the red blood cell. Circulation 139, 2654-2663.

Tejero, J., Kapralov, A.A., Baumgartner, M.P., Sparacino-Watkins, C.E., Anthonymutu, T.S., Vlasova, II, Camacho, C.J., Gladwin, M.T., Bayir, H., and Kagan, V.E. (2016). Peroxidase activation of cytoglobin by anionic phospholipids: Mechanisms and consequences. Biochim. Biophys. Acta. 1861, 391-401.

Tiso, M., Tejero, J., Basu, S., Azarov, I., Wang, X., Simplaceanu, V., Frizzell, S., Jayaraman, T., Geary, L., Shapiro, C., et al. (2011). Human neuroglobin functions as a redox-regulated nitrite reductase. J. Biol. Chem. 286, 18277-18289.

Tripatara, P., Patel, N.S., Webb, A., Rathod, K., Lecomte, F.M., Mazzon, E., Cuzzocrea, S., Yaqoob, M.M., Ahluwalia, A., and Thiemermann, C. (2007). Nitrite-derived nitric oxide protects the rat kidney against ischemia/reperfusion injury in vivo: role for xanthine oxidoreductase. J. Am. Soc. Nephrol. 18, 570-580. 
Velmurugan, S., Kapil, V., Ghosh, S.M., Davies, S., McKnight, A., Aboud, Z., Khambata, R.S., Webb, A.J., Poole, A., and Ahluwalia, A. (2013). Antiplatelet effects of dietary nitrate in healthy volunteers: involvement of cGMP and influence of sex. Free Radic. Biol. Med. 65, 1521-1532.

Wang, X., Tanus-Santos, J.E., Reiter, C.D., Dejam, A., Shiva, S., Smith, R.D., Hogg, N., and Gladwin, M.T. (2004). Biological activity of nitric oxide in the plasmatic compartment. Proc. Natl. Acad. Sci. U.S.A. 101, 11477-11482.

Wang L, Sparacino-Watkins CE, Wang J, Wajih N, Varano P, Xu Q, Cecco E, Tejero J, Soleimani M, Kim-Shapiro DB, et al. (2019). Carbonic anhydrase II does not regulate nitrite dependent nitric oxide formation and vasodilation. Br. J. Pharmacol. DOI: 10.1111/bph.14887. [Epub ahead of print].

Webb, A., Bond, R., McLean, P., Uppal, R., Benjamin, N., and Ahluwalia, A. (2004). Reduction of nitrite to nitric oxide during ischemia protects against myocardial ischemia-reperfusion damage. Proc. Natl. Acad. Sci. U.S.A. 101, 13683-13688.

Webb, A.J., Milsom, A.B., Rathod, K.S., Chu, W.L., Qureshi, S., Lovell, M.J., Lecomte, F.M., Perrett, D., Raimondo, C., Khoshbin,
E., et al. (2008a). Mechanisms underlying erythrocyte and endothelial nitrite reduction to nitric oxide in hypoxia: role for xanthine oxidoreductase and endothelial nitric oxide synthase. Circ. Res. 103, 957-964.

Webb, A.J., Patel, N., Loukogeorgakis, S., Okorie, M., Aboud, Z., Misra, S., Rashid, R., Miall, P., Deanfield, J., Benjamin, N., et al. (2008b). Acute blood pressure lowering, vasoprotective, and antiplatelet properties of dietary nitrate via bioconversion to nitrite. Hypertension 51, 784-790.

Weitzberg, E. and Lundberg, J.O. (1998). Nonenzymatic nitric oxide production in humans. Nitric Oxide 2, 1-7.

Yang, T., Zhang, X.M., Tarnawski, L., Peleli, M., Zhuge, Z., Terrando, N., Harris, R.A., Olofsson, P.S., Larsson, E., Persson, A.E.G., et al. (2017). Dietary nitrate attenuates renal ischemia-reperfusion injuries by modulation of immune responses and reduction of oxidative stress. Redox Biol. 13, 320-330.

Zweier, J.L., Wang, P., Samouilov, A., and Kuppusamy, P. (1995). Enzyme-independent formation of nitric oxide in biological tissues. Nat. Med. 1, 804-809. 